\title{
Em Parati foi assim...
}

MARIA CRISTINA S. ZELMANOVITS

Se o leitor está pensando que a seguir aparecerá o relato de uma experiência com começo, meio e fim, aviso logo: não é isso. 0 que será apresentado então? Apenas um começo... O projeto que envolve escolas e comunidades de Parati está em andamento e para se iniciar, precisará, no mínimo, de mais um ano.

Mas por que jogar luz em seu início? Porque inícios são marcas de batismo que podem sinalizar questões fundamentais para o desenvolvimento de uma história.

O Projeto de Educação na Escola e na Comunidade nasceu no segundo semestre de 2005, por iniciativa da Associação Cairuçu (www.cairucu.org), em parceria com o CENPEC. Tem como objetivo principal o aumento dos níveis de aprendizagem de crianças e adolescentes de cinco comunidades periféricas do município de Paraty, no Rio de Janeiro: Patrimônio, Ponta Negra, Quilombo Campinho da Independência, Sono e Laranjeiras.

Essas comunidades da região-meta caracterizam-se pela pobreza de seus habitantes, por um precário acesso aos serviços das políticas públicas, isolamento, cultura essencialmente oral e pouca valorização da escola e do letramento, exigência maior da sociedade contemporânea.

Muitas das escolas instaladas nessas comunidades são multisseriadas, limitando-se ao ensino de $1^{\underline{a}}$ a $4^{\underline{a}}$ séries. 0 ensino fundamental completo precisa se deslocar - o fato de estar no centro do município representa um grande obstáculo para a maioria prosseguir os estudos em virtude de inúmeras dificuldades, dentre elas, a de locomoção - em alguns lugares, apenas possível por meio de barcos ou trilhas, quando o tempo está favorável.

Os professores dessas escolas possuem uma formação ainda bastante incipiente. Nesse contexto, as taxas

MARIA CRISTINA S. ZeLMANOVITS é pedagoga, assessora da coordenação do CENPEC e já assessorou vários projetos de literatura e artes em escolas, museus e outras instituições. de evasão e reprovação acabam sendo superiores às da própria média do município.

Levando em conta as condições apontadas, foi proposto um projeto de ação que intervenha simultaneamente na escola - sobretudo na formação dos professores e na própria comunidade, principalmente pela ação de seus jovens que, ao mesmo tempo, ampliam seu universo informacional e cultural, promovendo oportunidades de aprendizagem em suas comunidades.

As concepções que fundamentam o projeto Educação na Escola e na Comunidade partem do pressuposto de que não basta agir na escola para se alcançar efetividade no aumento dos níveis de aprendizagem de crianças e adolescentes; a própria comunidade precisa valorizar o conhecimento letrado ganhando, ela mesma, aprendizagens novas que permitam a maior circulação e inclusão social nesta sociedade da informação e do conhecimento que nos toca viver.

\section{A parceria entre Associação Cairuçu e CENPEC}

\section{Entre 2005 e 2006, 0 CENPEC esteve em Parati por qua-} tro vezes para:

- conhecer as comunidades da região-meta;

- conversar com secretários municipais (da Educação, do Turismo e Cultura e da Promoção Social) e com algumas ONGs locais;

- realizar diagnósticos a respeito do ensino e da aprendizagem nas escolas, principalmente no que se refere ao trabalho com Língua Portuguesa;

- iniciar a formação dos jovens para a primeira experiência junto ao público infanto-juvenil - Programação de férias;

- iniciar a formação de professores que trabalham com as classes iniciais de alfabetização - crianças de cinco e seis anos - até a $2^{\underline{a}}$ série. 


\section{PROBLEMAS DA REGIÃO}

Dados do IBGE (2000) e do INEP (2003) nos permitem ter uma vista aérea, em que três problemas saltam aos olhos:

1. A oferta para a educação infantil não atende à demanda.

As matrículas nas pré-escolas, tanto rurais quanto urbanas, atingem apenas $30 \%$ da população infantil. A formação dos professores chega, no máximo, ao Ensino Médio completo. Se cruzarmos essas informações com as do item dois, podemos inferir que meninos e meninas têm entrado na ${ }_{1}{ }^{a}$ série sem condições de enfrentar o ensino formal de modo a obterem sucesso em suas aprendizagens.

2. As taxas de repetição na $1^{\underline{a}}$ e $2^{\underline{a}}$ séries são muito preocupantes.

A taxa de distorção idade-série no ensino fundamental é bastante alta. A formação dos professores que trabalham no município de $1^{\underline{a}}$ a $4^{\underline{a}}$ série não chega ao ensino universitário; entre os professores de $5^{\underline{a}}$ a $8^{\stackrel{a}{a}}$ série, aproximadamente, $47 \%$ têm ensino médio completo; e aproximadamente $53 \%$ têm universitário completo sem licenciatura. Como decorrência do comentário 1, temos aqui o efeito dominó do fracasso escolar nas séries posteriores.

3. O EJA precisa receber mais investimento. A disparidade de oferta de ensino deste segmento para a área urbana e rural é enorme. Não há escolas na área rural que atendem aos alunos de $6^{\underline{a}}, 7^{\underline{a}}$ e $8^{\underline{a}}$ séries. O número total de matrículas, nesse segmento do ensino, é muito baixo e a formação dos professores de EJA, a seguinte: mais da metade tem ensino médio completo e um pouco menos da metade tem universitário completo, sem licenciatura. Muitos dos alunos e alunas que conseguem terminar a $4^{\underline{a}}$ ou $5^{\underline{a}}$ séries não têm como continuar seus estudos.

Essas ações foram gerando, ao longo do tempo, avaliações que permitiram conhecer com mais profundidade as características, dificuldades, possibilidades, demandas e necessidades de cada lugar.

\section{Escolas}

\section{As escolas da Ponta Negra e do Sono são multisseria-} das e só oferecem aos alunos ensino até a $4^{\underline{a}}$ série. Além disso, localizam-se em lugares que não se constituem em ambientes letrados - constata-se a ausência de nomes nas poucas barracas que atendem aos turistas, de placas indicando caminhos das trilhas e outras sinalizações, enfim, as crianças dessas comunidades não convivem com a escrita em seu cotidiano.

Assim, faz-se necessário realizar um trabalho que, aos poucos, inclua as comunidades na cultura escrita e, ao mesmo tempo, respeite a estética desses ambientes tão belos. Um ambiente letrado promove um conjunto de situações de usos reais de leitura e escrita, nas quais as crianças têm a oportunidade de participar. Se o contexto e os adultos com quem as crianças convivem lhes oferecem oportunidade de presenciar, observar e atuar em diversos atos de leitura e de escrita, elas podem, desde cedo, pensar sobre a língua e seus usos, construindo idéias sobre como se lê e como se escreve.

Justamente porque pouquíssimas são as chances de convivência dessas crianças com a escrita, precisamos trabalhar com atividades de leitura que podem ocorrer tanto na escola quanto na comunidade. 0 universo de aprendizagens que compõe a leitura só se torna possível quando se elege o texto - ao contrário das palavras ou frases soltas - como unidade mínima de sentido para as crianças. É por meio de textos de uso real - ou seja, de textos que existem à nossa disposição, como receitas, cartas, listas, cardápios, outdoors, gibis, livros, revistas, placas, folders etc. - que podemos apresentar a elas os diferentes propósitos, a diversidade literária e a riqueza da linguagem que criam condições para que também se escreva melhor.

Em todas as escolas, incluindo as de Laranjeiras, Quilombo Campinho da Independência e Patrimônio, observa-se a necessidade de ampliar a formação dos professores e de organizar com eles uma rotina de trabalho que dê conta das aprendizagens fundamentais em leitura e escrita - o domínio da língua é fator de inclusão social e, ao mesmo tempo, base para a aprendizagem de outras áreas do conhecimento. Para se resolver um problema de Matemática, por exemplo, não basta saber as operações, é indispensável interpretar enunciados; para se compreender um texto de História ou Geografia, é preciso saber ler, relacionando dados e informações, saber diferenciar o que é informação geral e informação específica. 


\section{Comunidades}

\section{Nas comunidades da Ponta Negra e do Sono, os mora-} dores sobrevivem da pesca artesanal, da agricultura de subsistência, da exploração do turismo na alta temporada e do aluguel ou alojamento de turistas em suas casas e quintais. Entre as crianças e adolescentes que ajudam seus pais na lavoura e na pesca, muitos têm seus aprendizados escolares comprometidos ou até interrompidos por abandono.

A maior parte das famílias dessas comunidades vive em extrema pobreza, com dificuldades de acesso ao saneamento básico, à energia elétrica, ao transporte para Parati, aos equipamentos públicos de saúde, lazer, cultura, esportes. Há, portanto, fragilidades com relação à escola, à continuidade de ações propostas por organizações da sociedade civil e ao acesso aos bens culturais de Parati.

$\mathrm{Na}$ comunidade quilombola, que é inclusive Ponto de Cultura, observa-se uma identidade mais fortalecida. Existe a valorização da cultura negra e sua tradição no campo das artes, do artesanato, da culinária, do uso plantas medicinais. Mas, apesar da maior organização, há dificuldades para se integrarem ações da escola com ações já desenvolvidas na comunidade - oficinas de artesanato, pintura, cerâmica, vídeo, turismo étnico e outros. Embora a escola abra sua biblioteca e ofereça aulas de informática, parece não sair de si mesma e elaborar propostas coletivamente.

No Patrimônio e em Laranjeiras, muitos moradores trabalham como caseiros no Condomínio Laranjeiras e tem uma renda superior à das pessoas dos outros territórios investigados. Além disso, há a possibilidade de participação do universo informacional - o acesso à Internet mais facilitado, a convivência em ambiente letrado e a valorização da estética e da arte.

As lideranças comunitárias lutam pela implementação da educação para jovens e adultos, por espaços de sociabilidade e apreciam as conquistas da escola municipal e da associação de moradores.

Garantir o direito à educação básica em todas essas comunidades é um desafio possível, mas, para isso, são fundamentais a iniciativa e o envolvimento das pessoas que moram na comunidade. A compreensão dos pais, dos avós, das lideranças, das comunidades vizinhas e de toda a cidade sobre a importância de todas as crianças e adolescentes terem acesso à escola aponta rumos para o trabalho.
Contar com as potencialidades locais e criar espaços para as crianças, adolescentes e jovens desenvolverem atividades lúdicas, esportivas e culturais no contraturno escolar é uma estratégia que pode dar certo. 0 "dar certo" também depende de as comunidades assumirem a autoria e organização das atividades, identificando a importância desses espaços no desenvolvimento das crianças e formação dos jovens. Os agentes de saúde e a juventude das comunidades mostraram ser um caminho para mobilização e construção de projetos que produzam melhoria da qualidade de vida, assim como melhoria na aprendizagem de crianças e adolescentes.

\section{Primeiras ações}

\section{0 primeiro relatório elaborado pelo CENPEC determinou}

e priorizou as ações aprovadas pela diretoria e conselho da Associação Cairuçu. As primeiras sugestões acordadas e já realizadas foram:

- Construção de uma ponte na comunidade da Ponta Negra.

Essa pequena ação, que contou com a participação dos moradores, possibilitou a resolução de um problema que há anos vinha se estendendo e impossibilitava a ida de várias crianças à escola em dias de chuva forte. Quando queremos aumentar a freqüência e assiduidade escolar dos meninos e meninas, temos que pensar em diferentes estratégias - das mais simples às mais complexas.

- Capacitação de professores de crianças de cinco e seis anos e de $\mathbf{1}^{\mathrm{a}}$ e $\mathbf{2}^{\mathrm{a}}$ séries.

A capacitação contemplou todos os professores e coordenadores da região-meta e também foi aberta aos professores e coordenadores da rede municipal, constituindo um grupo de 35 profissionais.

- Capacitação de jovens das comunidades.

47 jovens das cinco comunidades da região-meta, mais a comunidade de Trindade, que acabou se agregando, elaboraram uma agenda de atividades para o mês de janeiro de 2006 - programação de férias;

- Programação de férias.

Realizada em janeiro de 2006, serviu como um projetopiloto para o conhecimento mais denso das comunidades e o estabelecimento de relações de confiança.

Durante a programação, foram propostas atividades às crianças e aos adolescentes das comunidades, visando aprofundar aprendizagens ligadas ao letramento - lei- 
tura e produção de texto -, arte, ampliação do repertório cultural, esporte, comunicação comunitária, questões do meio ambiente e ao protagonismo juvenil.
Os resultados do programa de férias, liderado pelos jovens das comunidades, permitiram-nos sistematizar, com eles, as aprendizagens:

\section{APRENDIZAGENS}

RELATIVAS Às CRIANÇAS E AOS ADOLESCENTES QUE

PARTICIPARAM DAS ATIVIDADES

\section{Questões ligadas a atitudes/convivência:}

- socialização dos saberes (conversa sobre os peixes, narrativas de histórias conhecidas e outros), ou seja, crianças e um adolescentes também podem assumir o lugar de informantes, podem se ensinar mutuamente, são capazes;

- organização de materiais e de diferentes funções nas atividades (trabalhar coletivamente);

- construção de vínculos afetivos;

- prestar atenção - acompanhar e compreender consignas das atividades -, olhar no olho, olhar para o outro.

Questões ligadas à ampliação de repertório cultural:

- conhecer elementos do lugar em que se vive (nomes de plantas, animais, cultura caiçara, cultura indígena, cultura africana, história de Parati etc.) e conhecer outras comunidades;

- narrativas - ouvir e contar histórias - ampliação do repertório literário.

\section{Questões ligadas à Ciência/Tecnologia:}

- meio ambiente, cadeia alimentar, animais e seus habitats/com portamentos, plantas, reciclagem etc.;

- $\quad$ rocedimentos de pesquisa em diferentes fontes de informação (pessoas da comunidade, livros, vídeos, Internet, visita a museus etc.);

- uso de recursos tecnológicos (manuseio do gravador, máquina fotográfica, filmadora, computador);

- produção de vídeo com a história da comunidade.

Questões ligadas à Arte:

- técnicas de artesanato, desenho/pintura e reconhecimento desse tipo de linguagem como outra possibilidade, para além da escrita, de representação de pensamentos, idéias, sentimentos etc.

Questões ligadas ao trabalho corporal:

- esportes: capoeira, futebol e surfe;

- ampliação de repertório de jogos e brincadeiras tradicionais.

Questões ligadas à Língua Portuguesa:

- realização de entrevistas (elaboração e registro de perguntas);

- produção de placas (elaboração de projeto, escrita com função social real - informar - e com destinatários reais);

- confecção de livro e produção de textos orais e escritos.

\section{RELATIVAS AOS JOVENS QUE}

COORDENARAM AS ATIVIDADES

Questões ligadas a atitudes/convivência:

- fortalecimento de laços de amizades entre os monitores da comunidade;

- ter paciência, respeitar os diferentes ritmos/saberes/jeitos das crianças e dos adolescentes de forma a trabalhar com a inclusão;

- reconhecimento da imensa capacidade das crianças/adolescentes quando se propõe algo verdadeiramente significativo para eles;

- reconhecimento das próprias limitações e habilidades/talentos.

Questões ligadas à ampliação de repertório cultural:

- conhecer outras comunidades, histórias, pessoas e lugares importantes de Parati;

- reconhecimento das riquezas e das potencialidades do lugar em que se vive e de seus entornos.

Questões ligadas ao trabalho:

- dar aula;

- atividades que mais interessam as crianças e os adolescentes;

- assumir responsabilidades;

- resolução de problemas: replanejar em função do inesperado;

- modelos de iniciativa e convocação para o trabalho;

- usar recursos tecnológicos para poder ensinar;

- trabalho com grupos heterogêneos;

- planejamento dos tempos/espaços de uma atividade mais específica (começo, meio e fim)/ lugar muito aberto não serve a determinadas propostas e vice-versa;

- antecipar questões relativas aos produtos finais (resolução de problemas relativos a capas, transcrições, edição etc.). 


\section{Patrimônio}

Além das aulas de desenho e capoeira, crianças e adolescentes participaram do projeto "Trilhas e Plantas". Ocorrendo três vezes por semana, no período da manhã, apresentou uma seqüência em que uma atividade criava condições para a seguinte.
Vejamos essa questão no projeto elaborado e coordenado pela jovem Thamis.

\section{PROGRAMAÇÃO DE FÉRIAS}

\section{SEMANA 1 \\ $1^{\circ}$ Encontro \\ Atividade}

Estudo a partir de vídeos com informações sobre árvores nativas do Brasil

\section{Programa}

Um pé de quê?, TV Futura, apresentado por Regina Casé.

\section{$2^{\circ}$ ENCONTRO}

\section{Atividade}

Continuação das pesquisas sobre árvores em livros e na Internet.

\section{$3^{\circ}$ Encontro}

\section{Atividade}

Criação de um viveiro para diferentes mudas de Árvores - preparo do solo (compostagem) e dos vasos para plantio.

\section{SEMANA 2}

$4^{\circ}$ E $5^{\circ}$ Encontros

Atividades

Trilha margeando

o rio Guarapitanga

e piquenique, com crianças e adolescentes da comunidade do Quilombo Campinho da Independência, pela qual passa o mesmo rio; coleta do lixo inorgânico encontrado e de amostras de água para análise.

\section{$6^{\circ}$ Encontro}

Atividade

Oficina de reciclagem; artes plásticas com lixo inorgânico e sementes.

\section{Semana 3 \\ $7^{\circ}$ EnCONTRO \\ Atividade}

Plantio de mudas de árvores nativas

- conhecimento dos estágios de crescimento das árvores e noções de Identificação de plantas.

\section{$8^{\circ}$ EnCONTRO \\ Atividade}

Confecção de placas de identificação para as mudas plantadas. Observação:

Placas feitas a partir de materiais reciclados, contendo informações pesquisadas: nome popular e científico, propriedades medicinais e curiosidades.

\section{$9^{\circ}$ EnCONTRO \\ Atividade}

Confecção de placas para a conservação de outra trilha - a que vai do Patrimônio até a aldeia indígena.

\section{SEMANA 4}

\section{$10^{\circ}$ EnCONTRO}

Atividade

Trilha para a aldeia indígena - explorá-la (conhecer suas árvores, plantas medicinais e cachoeiras) e colocar as placas confeccionadas.

\section{$11^{\circ}$ EnCONTRO}

Atividade

Visita à aldeia indígena Araponga - conhecimento da cultura indígena e almoço com os índios Tupiguaranis.

\section{$12^{\circ}$ EnCONTRO \\ Atividade}

Trilha para a aldeia indígena Araponga - plantio de mudas na Aldeia. 


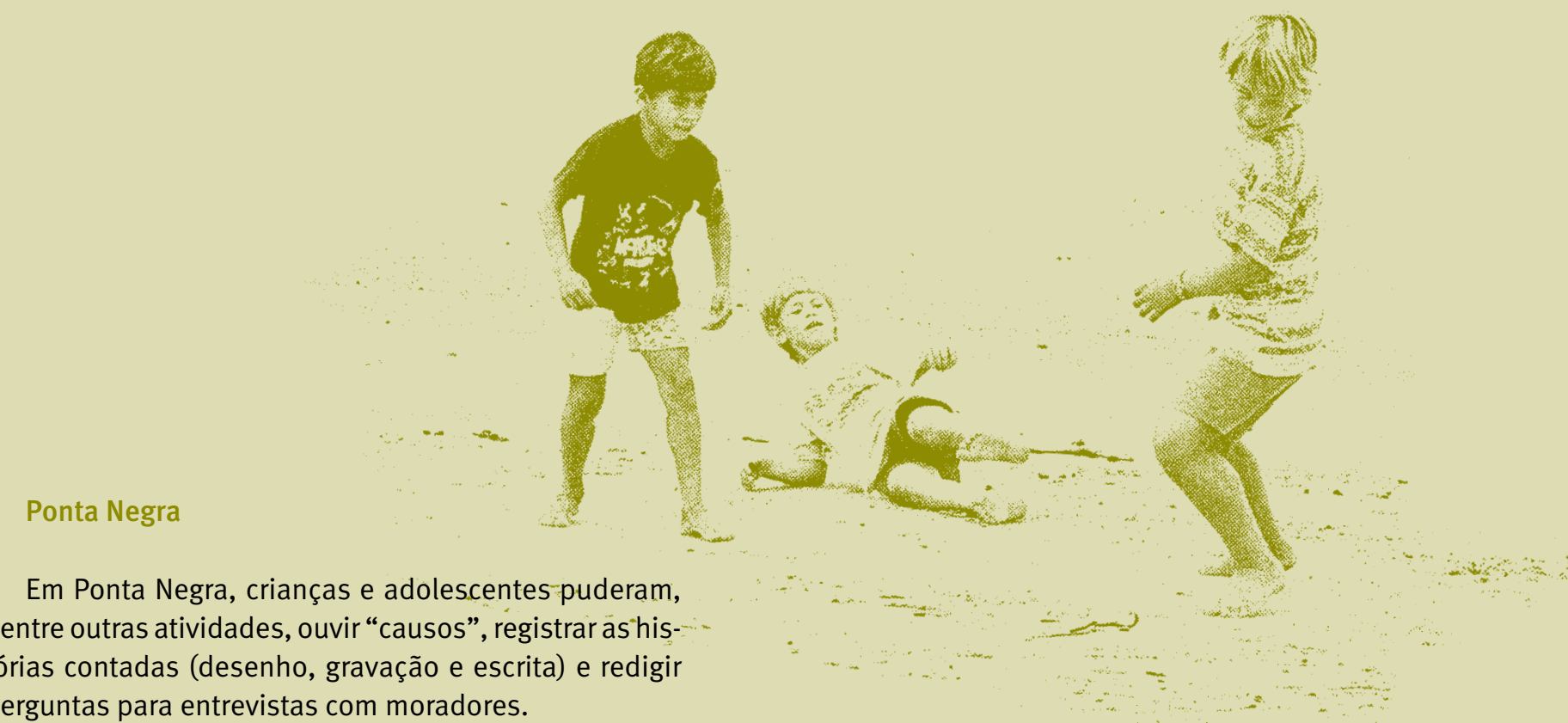
perguntas para entrevistas com moradores.

A importância de conhecer "causos" da comunidade se explica especialmente pelo resgate da cultura local: ao entrar em contato com esses textos, crianças e adolescentes têm a oportunidade de se apropriar da diversidade de temas e valores reconhecidos por seu povo e aprendem o valor da tradição oral.

Ao registrar os "causos" em gravadores ou por escrito, além de preservarem os textos da tradição oral (pois de outra forma correm o risco de se perder, já que, no mundo contemporâneo, a prática de contar histórias, infelizmente, é cada vez mais rara), crianças e adolescentes também têm a possibilidade de manter viva a enorme riqueza da cultura local, atualizando as preocupações, os valores morais, os desejos e, acima de tudo, a complexidade narrativa que organiza o imaginário de um povo.

Convidar pessoas reconhecidas como boas "contadoras de causos" para compartilhar suas histórias é uma experiência valiosa, pois, por meio dela, acolhem-se e se valorizam as manifestações populares e os próprios membros da comunidade. Isso também contribui para que crianças e adolescentes se sintam acolhidos e valorizados, na medida em que são parte dessa cultura.

Ouvindo "causos", tem-se a possibilidade de observar as condições necessárias para que uma história fique bem contada - tom de voz, relação com os ouvintes, utilização de recursos para criar climas de mistério ou para contar um trecho engraçado - e a emoção do contador contribua para dar mais vida à história.

\section{Quilombo Campinho da Independência}

A coleta de subsídios - entrevistas, filmagens, registros escritos e outros - realizada durante as quatro semanas da programação permitiu a elaboração de um vídeo como produto final. A confecção do vídeo envolveu diversas aprendizagens significativas: o mergulho na história

da comunidade para seu resgate e valorização; a integração entre crianças, adolescentes, jovens e adultos; a decisão compartilhada a respeito do que mostrar - e em que ordem - a partir de todo o material coletado etc.

Por que é importante conhecer a história do lugar em que se vive?

A partir do projeto, crianças e adolescentes tiveram oportunidade de aprofundar seus conhecimentos sobre sua comunidade e ressignificar seu vínculo com o espaço e com as pessoas: à medida que aprendem mais, conhecem sua história, apreciam sua beleza e se orgulham de pertencer ao grupo.

A abordagem concomitante dos principais problemas da comunidade - a ocupação do espaço, as questões de saneamento básico, a preservação do patrimônio biológico e tantos outros - também é uma forma de vinculação, pois, ao trazer à tona os principais problemas vividos pela população, incluem-se crianças e adolescentes na discussão da busca de alternativas para viabilizar um lugar melhor.

\section{Sono}

Embora nesta comunidade também se coloque em destaque a produção de placas para a comunicação visual das trilhas, vale contar que muitas crianças e adolescentes tiveram, por meio da programação, oportunidade de conhecer parte do patrimônio histórico de $\mathrm{Pa}$ rati pela primeira vez.

Uma cidade com essa riqueza cultural e arquitetônica, que luta para ter seu valor reconhecido pela humanidade, deve ser dada a conhecer aos seus próprios filhos, para que também possam assumir seu papel na tarefa de preservação.

Conhecer uma cidade inclui o olhar sobre os diferentes grupos étnicos e culturais que compõem a população, bem como explorar suas diversas manifestações - na ar- 
quitetura, nas festas comemoradas, nas histórias contadas pelo povo, no artesanato e principais motivos artísticos, na culinária local. Dessa forma, se favorece que a cidade não seja vista somente como espaço físico: ela é espaço humano, que abriga pessoas pertencentes a diferentes culturas, o que contribui para que se constitua de uma ou outra maneira.

Em Parati, por meio de passeios pelas ruas e de visitas a determinados locais, podemos encontrar: representantes de algumas nações indígenas, os europeus que se encantaram e ali fixaram moradia, os caiçaras das vilas de pescadores, a presença dos portugueses e sua importância na fundação da cidade, os quilombolas. Tais presenças são evidentes nas marcas arquitetônicas, nos edifícios pertencentes a diferentes momentos históricos, nas mais diversas manifestações populares ainda vivas pelas ruas da cidade.

\section{Trindade}

O tema "peixes da região" foi explorado de diversas maneiras e acabou virando livro. Na produção final, encontramos as características das diferentes espécies, desenhos, receitas de pratos que levam esse ingrediente e "causos" de pescadores registrados pelas crianças e adolescentes - tanto as receitas quanto os "causos" foram pesquisados na comunidade.

Para a confecção dos livros, crianças e adolescentes aprenderam técnicas de encadernação a partir de materiais recicláveis - a capa, por exemplo, foi feita com caixa de leite e rede de pesca.

\section{Laranjeiras}

Em destaque as atividades esportivas (surfe e futebol), a gincana da coleta de lixo e a recuperação da horta da escola por meio da limpeza, preparo da terra e plantio de mudas.

\section{0 que podemos dizer sobre o trajeto já percorrido}

\section{Uma primeira idéia que ajuda a responder à questão}

levantada no início deste texto - por que relatar apenas o começo de um projeto? -, e que é fundamental para a continuidade de uma história, se refere ao fato de, hoje em dia, já sabermos que um projeto socioeducacional é verdadeiramente eficaz quando apresenta co-autoria dos envolvidos na ação.
É preciso que as comunidades queiram, valorizem e reconheçam, como factíveis, o acesso ao conhecimento em geral e ao conhecimento escolar - daí a importância de projetos na comunidade e não apenas na escola.

Nossas primeiras ações partiram do pressuposto de que comunidades com baixa escolaridade e forte tradição oral exigem ações educacionais fora e dentro da escola. Essas ações envolvem articulação e negociação contínua e, por isso mesmo, não são uma camisa de força; comportam-se mais como uma pauta de prioridades e resultados.

No primeiro semestre de 2006, já faremos a aplicação de pesquisa avaliativa de pequenos impactos, levando em conta as crianças e adolescentes que participaram da programação de férias. A avaliação será feita nas escolas mediante entrevista com os professores, análise da ficha escolar dos alunos e um teste de aprendizagem. Os indicadores avaliativos de impacto referemse a: leitura, escrita, comunicação, expressão, argumentação; participação, cooperação e freqüência escolar. A idéia é envolver o grupo de jovens na aplicação e análise dos dados como oportunidade de desenvolvimento de capacidades.

Darvez e voz para crianças, adolescentes e jovens das comunidades tem nos ajudado a desenhar e redesenhar propostas cada vez mais ajustadas às necessidades, potencialidades e aos desejos de cada lugar. Não estaríamos conseguindo isso apenas contando com métodos mais tradicionais - pesquisa e coleta de dados, visitas, conversas e entrevistas com adultos das comunidades, do poder público, das escolas -, levantamento de principais necessidades/problemas e, em função deles, propostas unilaterais de encaminhamento.

Faz parte de nossa metodologia para o desenvolvimento comunitário, a reconstrução das prioridades e dos sentidos do que estamos fazendo, com os próprios beneficiários da ação. Do contrário, a ação social corre o risco de se esvaziar e não ser apropriada pelas comunidades.

As comunidades e escolas precisam compreender tais prioridades e acompanhar seu desempenho e resultados. Esse é o berço que estamos procurando construir juntos para ancorar a continuidade desta história!

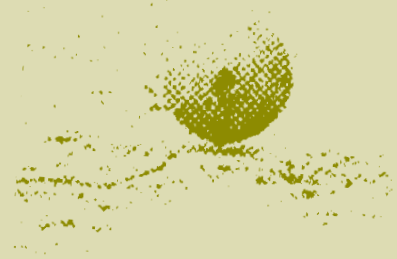




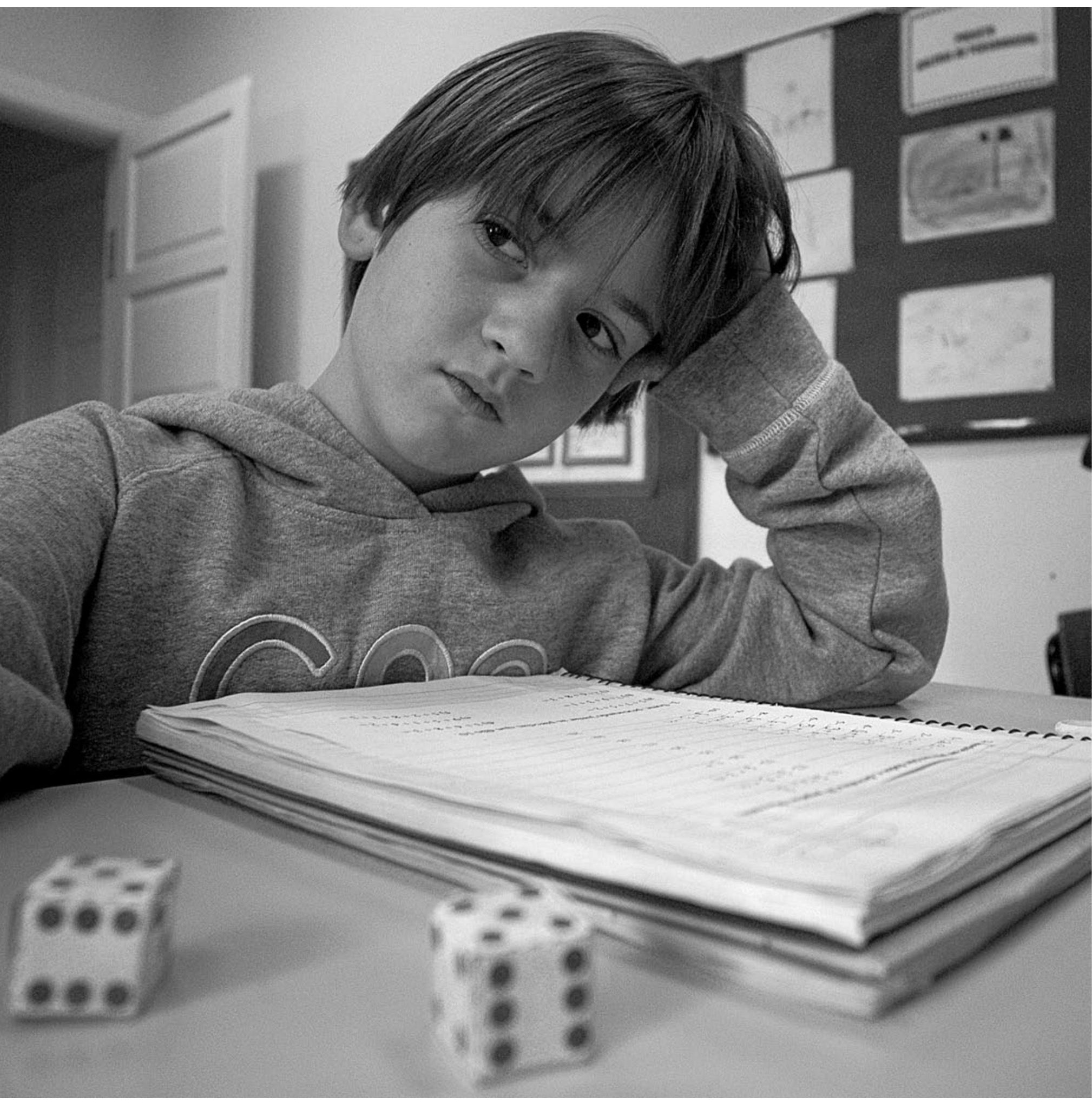

